\title{
Modeling the blow-blow forming process in glass container manufacturing : a comparison between computations and experiments
}

\author{
Citation for published version (APA): \\ Giannopapa, C. G., \& Groot, J. A. W. M. (2011). Modeling the blow-blow forming process in glass container \\ manufacturing : a comparison between computations and experiments. (CASA-report; Vol. 1128). Technische \\ Universiteit Eindhoven.
}

\section{Document status and date:}

Published: 01/01/2011

\section{Document Version:}

Publisher's PDF, also known as Version of Record (includes final page, issue and volume numbers)

\section{Please check the document version of this publication:}

- A submitted manuscript is the version of the article upon submission and before peer-review. There can be important differences between the submitted version and the official published version of record. People interested in the research are advised to contact the author for the final version of the publication, or visit the $\mathrm{DOI}$ to the publisher's website.

- The final author version and the galley proof are versions of the publication after peer review.

- The final published version features the final layout of the paper including the volume, issue and page numbers.

Link to publication

\footnotetext{
General rights

- You may freely distribute the URL identifying the publication in the public portal. follow below link for the End User Agreement:

www.tue.nl/taverne

\section{Take down policy}

If you believe that this document breaches copyright please contact us at:

openaccess@tue.nl

providing details and we will investigate your claim.
}

Copyright and moral rights for the publications made accessible in the public portal are retained by the authors and/or other copyright owners and it is a condition of accessing publications that users recognise and abide by the legal requirements associated with these rights.

- Users may download and print one copy of any publication from the public portal for the purpose of private study or research.

- You may not further distribute the material or use it for any profit-making activity or commercial gain

If the publication is distributed under the terms of Article $25 \mathrm{fa}$ of the Dutch Copyright Act, indicated by the "Taverne" license above, please 


\section{EINDHOVEN UNIVERSITY OF TECHNOLOGY}

Department of Mathematics and Computer Science

\section{CASA-Report II-28 \\ April 2OII}

Modeling the blow-blow forming process in glass container manufacturing:

A comparison between computations and experiments

by

C.G. Giannopapa, J.A.W.M. Groot

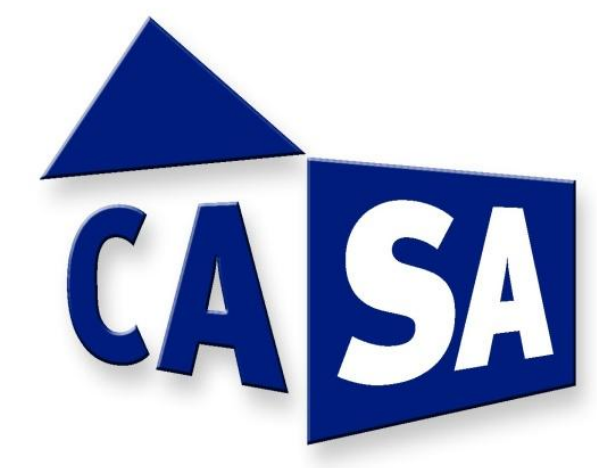

Centre for Analysis, Scientific computing and Applications

Department of Mathematics and Computer Science

Eindhoven University of Technology

P.O. Box 513

5600 MB Eindhoven, The Netherlands

ISSN: 0926-4507 



\title{
Modeling the Blow-Blow Forming Process in Glass Container Manufacturing: A Comparison between Computations and Experiments
}

\author{
C. G. Giannopapa \\ Dept. of Math. and Computer Science \\ Eindhoven University of Technology \\ PO Box 513, 5600 MB Eindhoven \\ The Netherlands \\ Email: c.g.giannopapa@tue.nl \\ J. A. W. M. Groot \\ Dept. of Math. and Computer Science \\ Eindhoven University of Technology \\ PO Box 513, 5600 MB Eindhoven \\ The Netherlands \\ Email: j.a.w.m.groot@tue.nl
}

\begin{abstract}
The blow-blow forming process is a widely used technique in glass container manufacturing (e.g. production of glass bottles and jars). This process typically takes few seconds and is characterized by large deformations and temperature gradients. In [1] the development of a computer simulation model for glass blowing was presented and demonstrated on dummy problems with an initially uniform glass temperature. The objective of this paper is to extend and further develop the simulation model to be used for industrial purposes. To achieve this both steps of the blow-blow forming process of glass containers are simulated and tested against real industrial problems. In this paper a non-uniform temperature distribution is considered for the blowing of the preform, which is reconstructed from temperature data provided by industry. The model is validated by means of several examples regarding conservation properties, behaviour of the flow and comparison of the glass thickness with experimental measurements. Furthermore, by means of these examples the sensitivity of the glass thickness to inaccuracies in the measurement and reconstruction of the initial temperature distribution is verified.
\end{abstract}

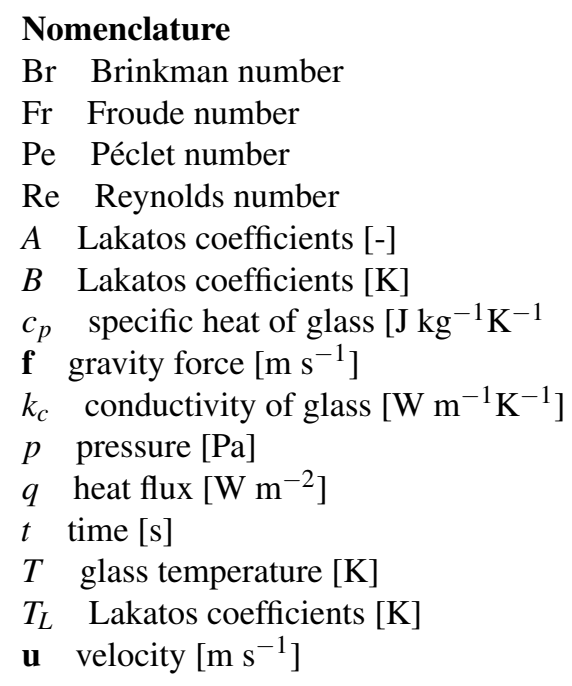


$\mu \quad$ (dynamic) viscosity $\left[\mathrm{kg} \mathrm{m}^{-1} \mathrm{~s}^{-1}\right]$

$\rho$ density $\left[\mathrm{kg} \mathrm{m}^{-3}\right]$

$\sigma \quad$ stress tensor $[\mathrm{Pa}]$

$\phi \quad$ level set function

\section{Introduction}

For centuries glass forming of containers, such as bottles, jars and art articles, was performed by hand and was based on empirical knowledge and hands on experience. In the 19th century glass containers were produced by an automated process in which molten glass is molded by inflating it with compressed air. Since then there has been a significant progress in understanding and optimizing the glass manufacturing process [2,3].

A forming process in the glass container manufacturing circle is typically comprised of two stages. Two widely used glass container forming techniques are the blow-blow method and the press-blow method. A schematic drawing of the blowblow process can be seen in Fig. 1. The molten glass that is used for the forming process comes straightly from the furnace, where temperatures can go up to $1500^{\circ} \mathrm{C}$. After the melt leaves the furnace, it passes through a feeder and is cut into uniform gobs by a shearing and distribution system. Each gob is sent to an individual section forming machine, where the gob is forced to take the mould shape, while the temperature drops below $1150{ }^{\circ} \mathrm{C}$. The blow-blow forming machine consists of two moulds: one for each blow stage of the process. In the first blow stage the gob is delivered into the mould from above (Fig. 1(a)) and pressurized air blows the gob to the base of the mould to form the neck of the bottle (Fig. 1(b)). Compressed air is then blown from the bottom of the mould forcing the inner part of the gob to rise and take the shape of the mould (Fig. 1(c)) forming a thick walled preform or parison. Then the parison is removed by a robotic arm from the first mould, turned upside down and transferred to another mould for the second blow stage (Fig. 1(d)). Here the preform is left to sag due to gravity until it nearly touches the bottom of the mould. Subsequently, pressurized air is used to inflate the preform until it takes the final container shape (Fig. 1(e)). The container is then removed from the mould (Fig. 1(f)) and transferred to an annealing oven where it is reheated to remove the stress produced during forming. Finally, it is cooled under controlled conditions.

(a)
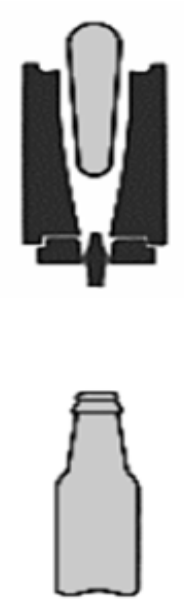

(d) (b)
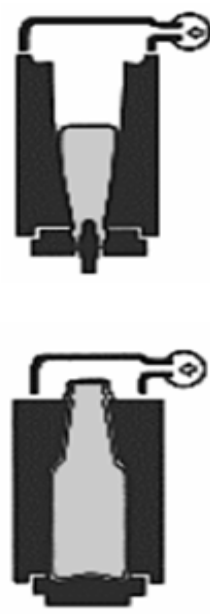

(e) (c)

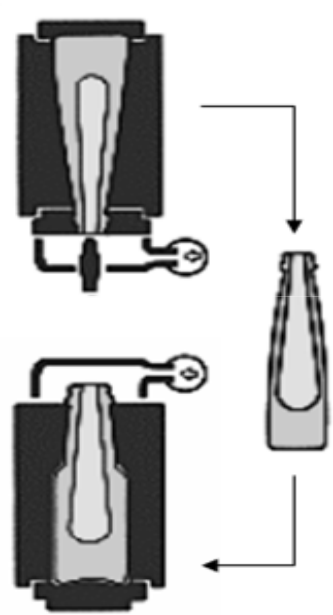

(f)

Fig. 1. SCHEMATIC DRAWING OF A BLOW-BLOW PROCESS

Computer model simulations have become increasingly important in optimizing and controlling glass forming processes as they give insight in the phenomena happening fast and at extremely high temperature conditions. Simulations offer a good alternative to time consuming and expensive trial and error procedures common to factories. Representative numerical simulations could help minimize unwanted variations in wall thickness of containers and reduce their weight while maintaining the strength. They can also help optimize cooling conditions and increase the production speed.

Throughout the years various glass blow simulation models have been developed [4-7]. Most papers focus on modeling merely the final blow stage in either the blow-blow or the press-blow process. Only few papers have modeled the complete press-blow process [6] or the complete blow-blow process [8]. 
In [1] the development of a computer model to be used for glass blowing was described and demonstrated on dummy problems. The model in [1] was able to take as input information a relatively simple preform shape, a uniform temperature of the preform and the mould and a prescribed inlet air pressure. The model was merely validated by verification of volume conservation, but not tested against industrial data. The simulation model uses level set methods to track the glass-air interfaces. A major advantage of level set methods is that no re-meshing is required to distinguish between the glass domain and the air domain in time; the location of the interface can be marked by the so-called level set function instead [9-12].

This paper concentrates on modeling the full blow-blow forming process of glass containers with realistic data provided by glass manufacturers. In particular it is focused on the accurate representation of the glass-air interfaces during blowing and the correct thickness of the final product. The objective of this paper is to create a robust computational model to be used for industrial purposes which can accurately capture the blow-blow forming process of glass containers. The model should be able to take as input information the gob volume or the glass preform shape, a temperature distribution of the gob or preform and the mould and a prescribed inlet air pressure. It should output the container preform or final shape, the products final wall thickness as well as the stress and thermal deformations the preform and the mould undergo during the process. The model is validated by means of several examples regarding conservation properties, behaviour of the flow and comparison of the glass thickness with experimental measurements.

\section{Mathematical Formulation}

This section is concerned with presenting the mathematical model used to describe both blow stages of the production process. This involves solving the motion of glass and air, the heat exchange in glass and air and the position of the glass-air interface.

\subsection{Flow problem}

The motion of both the glass melt and the pressurized air can be described by the Navier-Stokes equations for incompressible fluids.

Momentum equation:

$$
\rho\left(\frac{\partial \mathbf{u}}{\partial t}+\mathbf{u} \cdot \nabla \mathbf{u}\right)=\nabla \cdot \sigma+\rho \mathbf{f}
$$

Continuity equation:

$$
\nabla \cdot \mathbf{u}=0
$$

At high temperatures glass behaves as a Newtonian fluid [3,13]. For Newtonian fluids the constitutive equation for the stress tensor is given by:

$$
\sigma=2 \mu \dot{\varepsilon}-p \mathbf{I}
$$

where $\dot{\varepsilon}$ is the strain rate tensor:

$$
\dot{\varepsilon}=\frac{1}{2}\left(\nabla \mathbf{u}+\nabla \mathbf{u}^{T}\right)
$$

Here the dynamic viscosity of glass depends on the temperature $T$ :

$$
\mu \equiv \mu(T)
$$

By substituting (3) into (1) the momentum equation can be rewritten in the form

$$
\rho\left(\frac{\partial \mathbf{u}}{\partial t}+\mathbf{u} \cdot \nabla \mathbf{u}\right)=2 \nabla \cdot(\mu \dot{\varepsilon})-\nabla p+\rho \mathbf{f}
$$


In order to further analyze the problem quantitatively equation (6) is made dimensionless. Let us consider a typical: velocity $U_{0}$, length scale $L_{0}$, viscosity $\mu_{0}$ and pressure $p_{0}$. The characteristic pressure for the glass domain can be derived from

$$
p_{0}=\frac{\mu_{0} U_{0}}{L_{0}}
$$

and for the air domain from

$$
p_{0}=\rho_{0} U_{0}^{2}
$$

Define dimensionless time, length, velocity, pressure and gravitational body forces:

$$
t^{*}=\frac{U_{0} t}{L_{0}}, \quad x^{*}=\frac{x}{L_{0}}, \quad \mathbf{u}^{*}=\frac{\mathbf{u}}{U_{0}}, \quad p^{*}=\frac{p}{p_{0}}, \quad \mathbf{f}^{*}=\frac{\mathbf{f}}{\|\mathbf{f}\|} .
$$

The dimensionless form of the momentum (6) and the continuity equation (2) are:

$$
\begin{aligned}
& \frac{\partial \mathbf{u}^{*}}{\partial t^{*}}+\mathbf{u}^{*} \cdot \nabla^{*} \mathbf{u}^{*}=\frac{2}{\operatorname{Re}} \nabla^{*} \cdot\left(\mu^{*} \dot{\varepsilon}^{*}\right)-\frac{p_{0}}{\rho U_{0}^{2}} \nabla^{*} p^{*}+\frac{1}{\operatorname{Fr}} \mathbf{f}^{*} \\
& \nabla^{*} \cdot \mathbf{u}^{*}=0 .
\end{aligned}
$$

Here the ratio of the inertial forces to viscous forces is described by the Reynolds number,

$$
\operatorname{Re}=\frac{\rho U_{0} L_{0}}{\mu_{0}}
$$

and the ratio of the inertial forces to the gravitational force is given by the Froude number,

$$
\operatorname{Fr}=\frac{U_{0}^{2}}{L_{0}\|\mathbf{f}\|}
$$

Boundary conditions for the flow problem are:

- an inflow pressure $p=p_{\text {in }}$ at the mould entrance,

- free-stress conditions for air and no-slip conditions for glass on the mould wall,

- 2D axial symmetry conditions on the symmetry axis.

\subsection{Heat exchange}

The heat flow can be described by the energy equation and for an incompressible fluid in an Eulerian description it reads:

$$
\rho c_{p}\left(\frac{\partial T}{\partial t}+\mathbf{u} \cdot \nabla T\right)=-\nabla \cdot \mathbf{q}+2 \mu \dot{\varepsilon}: \nabla \mathbf{u}
$$

Here $c_{p}$ is the specific heat of the glass and $\mathbf{q}$ is the heat flux. The heat flux $\mathbf{q}$ is the result of the contribution of both thermal conduction and radiation. The calculation of radiative heat transfer is in general a complicated process. However, for clear glasses it is usually reasonable to omit the radiative conductivity $[14,15]$. Therefore, the heat transfer due to radiation is neglected and it is assumed that the conduction obeys the Fourier law, which relates the heat flux vector to the temperature $T$ by thermal conductivity $\mathrm{k}$ as

$$
\mathbf{q}=-k \nabla T \text {. }
$$


Thus, the energy equation can be written as

$$
\rho c_{p}\left(\frac{\partial T}{\partial t}+\mathbf{u} \cdot \nabla T\right)=-k \nabla^{2} T+2 \mu \dot{\varepsilon}: \nabla \mathbf{u}
$$

Define dimensionless viscosity and temperature,

$$
\mu^{*}=\frac{\mu}{\mu_{0}}, \quad T^{*}=\frac{T-T_{m}}{T_{g}-T_{m}}
$$

where $T_{m}$ is the temperature of the mould and $T_{g}$ is the typical glass temperature. The dimensionless form of the energy equation (15) reads

$$
\operatorname{Pe}\left(\frac{\partial T^{*}}{\partial t^{*}}+\mathbf{u}^{*} \cdot \nabla^{*} T^{*}\right)=-\nabla^{* 2} T^{*}+2 \operatorname{Br} \mu^{*} \dot{\varepsilon}^{*}: \nabla^{*} \mathbf{u}^{*}
$$

The forced convection of a system is related to its heat conduction by the Péclet number,

$$
\mathrm{Pe}=\frac{\rho c_{p} L_{0} U_{0}}{k},
$$

and the effect of viscous dissipation is related to the effect of conduction by the Brinkman number,

$$
\mathrm{Br}=\frac{\mu_{0} U_{0}^{2}}{k\left(T_{g}-T_{m}\right)}
$$

The boundary conditions for the energy problem follow from symmetry,

$$
(\lambda \nabla T) \cdot \mathbf{n}=0
$$

and heat exchange with the mould,

$$
(\lambda \nabla T) \cdot \mathbf{n}=\alpha\left(T-T_{m}\right)
$$

where $\alpha\left[\mathrm{W} \mathrm{m}{ }^{-2} K^{-1}\right]$ is the heat transfer coefficient.

The viscosity typically represents the fluids' resistance to the flow. The viscosity of glass strongly depends on the temperature. Consequently, the flow problem and the energy problem are coupled. As the temperature rises the viscosity decreases. In the temperature range of the blow-blow process a good fit to the viscosity data is provided by the so-called Vogel-Fulcher-Tammann (VFT) relation [2,13]:

$$
\mu(T)=10^{-A+B /\left(T-T_{L}\right)} .
$$

where $A, B, T_{L}$ are the Lakatos coefficients, which are empirically determined depending on the type of the glass. In Figure 2 a curve fit of the viscosity data by the VFT equation is shown. The Lakatos coefficients for the curve fit are given in Tab. 1. The data was provided by industry.

\subsection{Glass-air interface position: Level set methods}

The problems that this paper intends to model involve moving interfaces. A level set method has been chosen to capture the moving interfaces between the two continua: glass and air $[9,10]$. This method allows to model flows with moving interfaces using a fixed spatial domain. Usually, two continua with different densities and viscosities are considered. The basic idea is to embed a moving interface as the zero level set of the so-called interface or level set function $\phi$, which serves 


\begin{tabular}{llll}
\hline Coefficient [Unit] & $A[-]$ & $B[\mathrm{~K}]$ & $T_{L}[\mathrm{~K}]$ \\
\hline Value & 2.76 & $5.69 \cdot 10^{3}$ & $1.89 \cdot 10^{2}$ \\
\hline
\end{tabular}

Table 1. Lakatos coefficients for the curve fit of the glass viscosity data by the VFT equation.

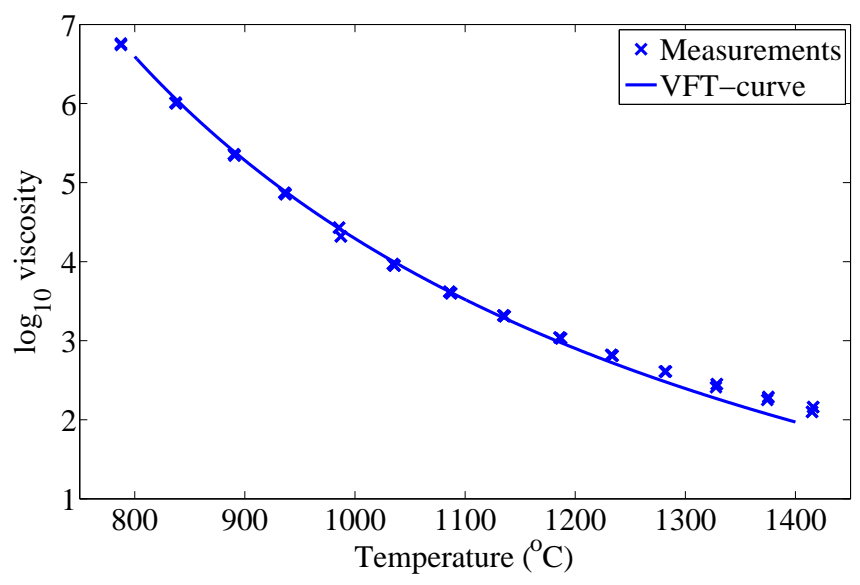

Fig. 2. Curve fit of the glass viscosity data by the VFT equation.

as a marker identifying the interface between the two continua, while the continua can easily be distinguished by the sign of the interface function. The evolution of the zero level set, thus the motion of the interface, is governed by the convection equation:

$$
\frac{\partial \phi}{\partial t}+\mathbf{u} \cdot \nabla \phi=0
$$

Thus, at any time $t$ the corresponding interface is given implicitly by $\phi(\mathbf{x}, t)=0$. For the simulations two level set methods are used, one describing the position of the inner interface of the perform and the other the position of the outer one.

\section{Discretisation Method}

Finite element methods $[16,17]$ have been used for the discretization of the Stokes flow problem, the level set problem and the energy problem. The finite element formulation has been implemented in a SEPRAN finite element package. Minielements are used for the computations [18].

The resulting equations are solved using the BI-CGSTAB method [19]. This iterative method terminates after a finite number of iteration steps. As a stopping criterion the absolute value of the residual less than $10^{-8}$ is used for the Stokes flow problem and the level set problem and $10^{-6}$ for the energy problem. As an initial guess for the iteration process the solution obtained in the previous time step is used. For the energy problem the stabilized formulation is obtained using the streamline-upwind Petrov-Galerkin (SUPG) method [20,21].

The Euler Implicit scheme was used for the time integration. Each time step successively the static Stokes flow problem, the energy problem and the level set problems are solved in respective order. The flow velocity obtained from the Stokes flow problem is used to solve the energy problem and the level set problems, the temperature obtained from the energy problem is used to compute the viscosity for the next time step and the level set functions obtained from the level set problems are used to track the location of the interfaces in the next time step.

A level set method is used for capturing the two-fluid flow interfaces. Level set methods compute geometric properties of highly complicated boundaries without necessarily explicitly tracking the interface. Furthermore, the moving interface can undergo topological changes, i.e. develop corners quite naturally.

One of the difficulties encountered in level set methods is to keep the desired shape of the level set function. When the flow velocity in the domain is not constant, the level set function can deform such that it introduces numerical difficulties. There are two basic solutions to this problem:

(a) to adapt the velocity field; a procedure of extending velocities that is mainly used for problems where the velocity is only known at the interface, 
(b) to re-initialize the level set function, in which case the velocity field remains unchanged.

In this case the velocity field is kept unchanged and the level set function is re-initialized. The level set function $\phi$ is initially a Euclidean distance function to the corresponding interface $\Gamma(t)$, i.e.

$$
\|\nabla \phi(\mathbf{x}, 0)\|_{2}=1 .
$$

As the interface is convected by the flow velocity according to equation (23), the gradient of the function $\phi$ deviates from 1 and may become increasingly irregular. The initially well-shaped level set function can develop steep gradients on one side and can become almost constant on the other side of the domain. Therefore, it is desirable to compute a so-called signed distance function $d$, that has the following properties while the sign of the distance function changes across the interface:

$$
\begin{aligned}
\|\nabla d\|_{2} & =1, \\
d & =0, \quad \text { on } \Gamma(t) .
\end{aligned}
$$

The re-initialization technique used in this paper is based on triangulated fast marching methods and can be used for computations in both structured and unstructured meshes. Further details can be found in [1]. The signed distance function to the inner interface on the mould surface immediately gives the product thickness, provided the outer interface coincides with the mould surface.

\section{Computer Simulation Model}

This section presents the computer simulation model for the blow-blow process. The simulations considered are tested on commercial bottle containers. Simulations were performed both for the first blow stage as well as the second blow stage. The preform's outer shape in the second blow stage has been used as the mould shape for the first blow stage. Both blow stages are simulated for given time durations. The information regarding the dimensions and the manufacturing conditions were supplied by manufacturers. The time durations of the blow stages were not explicitly given by manufacturers, but were chosen reasonably small, such that at least a complete mould shape could be blown. Once the mould is completely covered with glass, changes in the mould shape due to blowing will be marginal. Finally, the bottle thickness in the simulation is validated by comparing it with measured thickness data.

In the mould for the first blow stage the neck formation and the initial compression of the gob by pressurized air are not considered. The simulation starts after the gob is settled. The motion of the glass melt is captured by the level set method. Typical values used in the simulations are given in Tab. 2.

The momentum equation (10a) can be simplified based on the following arguments. Because of the low Reynolds number, the flow of glass is driven by viscous forces. However, this is not the case for air. As a matter of fact, for the inlet air the typical pressure can be chosen as $p_{0}=p_{\text {in }}$ rather than (8). Then for air,

$$
\frac{p_{0}}{\rho U_{0}^{2}} \sim 1.38 \cdot 10^{9},
$$

from which the momentum equation (10a) could be reduced to

$$
\nabla p=0 .
$$

However, in order to restrict the number of degrees of freedom, the pressure should be coupled to the flow velocity in the momentum equation. Then because of the moderate Reynolds number for air the full Navier-Stokes equations should be solved, which is computationally expensive. Moreover, mainly the flow of glass is of interest for the simulations. Therefore, for the simulations the air is replaced by a fictitious fluid with viscosity $\mu=2.1 \mathrm{~Pa}$ s and density $\rho=1 \mathrm{~kg} \mathrm{~m}^{-3}$. For the fictitious fluid the Reynolds number is $4.76 \cdot 10^{-5}$. As $\mathrm{Re} \ll 1$ for both glass and air the problem is dominated by viscous and gravitational forces and the inertia terms may be neglected. On the other hand, the viscosity of the fictitious fluid is still

much smaller than the viscosity of glass, so that the pressure drop in the air domain is negligible compared to the pressure drop in the glass domain $[1,22]$. Thus, the flow problem for both glass and fictitious fluid can be simplified by solving the Stokes flow equations (omitting *):

$$
\begin{aligned}
& \frac{2}{\operatorname{Re}} \nabla \cdot(\mu \dot{\varepsilon})=\frac{p_{0}}{\rho U_{0}^{2}} \nabla p+\frac{1}{\operatorname{Fr}} \mathbf{f} \\
& \nabla \cdot \mathbf{u}=0 .
\end{aligned}
$$




\begin{tabular}{llll}
\hline Quantity & Symbol [Unit] & \multicolumn{2}{c}{ Typical value } \\
& & Glass & Air \\
\hline Characteristic length & $L_{0}[\mathrm{~m}]$ & $10^{-2}$ & \\
Characteristic velocity & $U_{0}\left[\mathrm{~m} \mathrm{~s}^{-1}\right]$ & $10^{-2}$ & \\
Viscosity & $\mu\left[\mathrm{kg} \mathrm{m}^{-1} \mathrm{~s}^{-1}\right]$ & $10^{4}$ & $10^{-5}$ \\
Density & $\rho\left[\mathrm{kg} \mathrm{m}^{-3}\right]$ & $2.53 \cdot 10^{3}$ & 1.00 \\
Inlet pressure & $p_{\text {in }}[\mathrm{Pa}]$ & $1.38 \cdot 10^{5}$ & \\
Thermal conductivity & $k\left[\mathrm{~W} \mathrm{~m}{ }^{-1} \mathrm{~K}^{-1}\right]$ & 1.40 & $3 \cdot 10^{-2}$ \\
Specific heat & $c_{p}\left[\mathrm{~J} \mathrm{~kg} \mathrm{~K}{ }^{-1}\right]$ & $1.40 \cdot 10^{3}$ & $10^{3}$ \\
Temperature & $T[\mathrm{~K}]$ & $10^{3}$ & $8 \cdot 10^{2}$ \\
Mould temperature & $T_{m}[\mathrm{~K}]$ & $5 \cdot 10^{2}$ & \\
Reynolds number & $\operatorname{Re}[-]$ & $2.53 \cdot 10^{-5}$ & 10 \\
Froude number & $\operatorname{Fr}[-]$ & $10^{-3}$ & \\
Péclet number & $\operatorname{Pe}[-]$ & $2.53 \cdot 10^{2}$ & 3.33 \\
Brinkman number & $\mathrm{Br}[-]$ & $1.42 \cdot 10^{-3}$ & $1.11 \cdot 10^{-10}$ \\
\hline
\end{tabular}

Table 2. Typical values for the blow-blow process

The influence of dissipation in the energy equation (17) can be neglected as $\mathrm{Br} \ll 1$. The Brinkman number of the fictitious fluid is $2.34 \cdot 10^{-5}$.

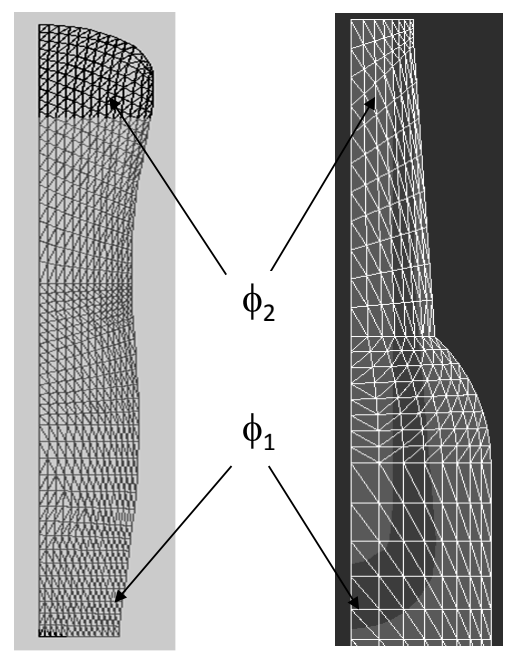

(a)

(b)

Fig. 3. Finite element mesh and interface representation: (a) preform (b) bottle.

Two level set functions were used to capture the moving interfaces; one for the outer interface and one for the inner interface. Simulations were performed using both structured and unstructured meshes. Graphs of the finite element mesh can be found in Fig. 3.

It is common practice in glass manufacturing that there is a temperature variation in the glass preform, which results in wall thickness variations. Thus, a non-uniform initial temperature distribution was considered for the second blow of the preform. The temperature data was provided by industry and fitted by the function by means of multiple linear regression:

$$
T_{0}(r, z)=T_{0}\left(1-\lambda_{z} e^{-\kappa_{z} z}\right)+\sum_{k=1}^{4}(-1)^{k}\left(T_{k, r} r^{k}+T_{k, z} z^{k}\right)
$$


Here coordinate $r$ is in radial direction of the mould and coordinate $z$ is in axial direction with $z=0 \mathrm{~m}$ at the lowest point of the mould. The coefficients were determined by means of least squares and are given in Tab. 3. Figure 4 compares the temperature data with the least squares approximation in (29). The root mean square error of the approximation is $15.08^{\circ} \mathrm{C}$.

\begin{tabular}{ll}
\hline Coefficient [Unit] & value \\
\hline$T_{0}[\mathrm{~K}]$ & $3.2104 \cdot 10^{3}$ \\
$T_{1, r}\left[\mathrm{Km}^{-1}\right]$ & $6.9036 \cdot 10^{4}$ \\
$T_{2, r}\left[\mathrm{Km}^{-2}\right]$ & $1.7209 \cdot 10^{7}$ \\
$T_{3, r}\left[\mathrm{Km}^{-3}\right]$ & $1.3748 \cdot 10^{9}$ \\
$T_{4, r}\left[\mathrm{Km}^{-4}\right]$ & $3.2284 \cdot 10^{10}$ \\
$T_{1, z}\left[\mathrm{Km}^{-1}\right]$ & $4.4453 \cdot 10^{4}$ \\
$T_{2, z}\left[\mathrm{Km}^{-2}\right]$ & $3.0587 \cdot 10^{5}$ \\
$T_{3, z}\left[\mathrm{Km}^{-3}\right]$ & $6.9616 \cdot 10^{5}$ \\
$T_{4, z}\left[\mathrm{Km}^{-4}\right]$ & 0.0 \\
$\lambda_{z}[-]$ & $3.3887 \cdot 10^{5}$ \\
$\kappa_{z}\left[\mathrm{~m}^{-1}\right]$ & $2.0 \cdot 10^{2}$ \\
\hline
\end{tabular}

Table 3. Coefficients in interpolation formula for the non-uniform temperature distribution

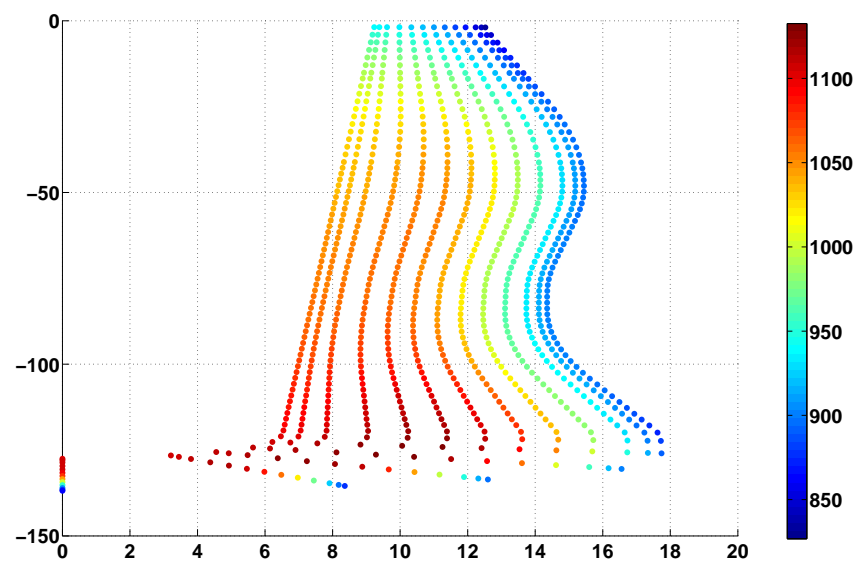

(a) Data $\left[{ }^{\circ} \mathrm{C}\right]$

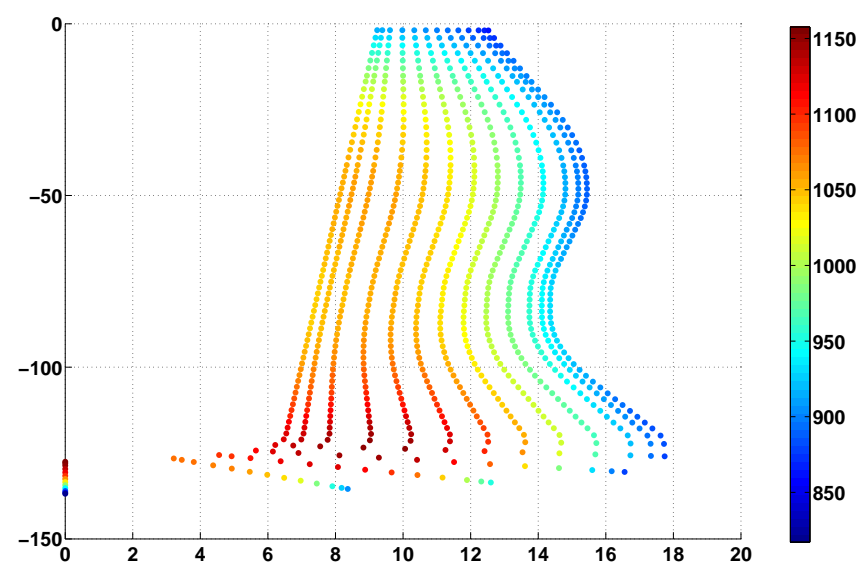

(b) Approximation in data points $\left[{ }^{\circ} \mathrm{C}\right]$

Fig. 4. Temperature distribution of preform.

\section{Results}

For the simulations of the first blow stage the initial temperature of air and the mould were $500^{\circ} \mathrm{C}$. The initial temperature of the gob was considered to be uniform. The propagation of the glass during the first blow stage can be seen in Fig. 5 . The area of glass is depicted with red and the area of air is depicted with blue. The temperature profiles at the corresponding times can be seen in Fig. 6. The time duration of the first blow stage is $1.75 \mathrm{~s}$.

In the second blow stage the preform is first let inside the mould to sag due to gravity long enough that it just does not touch the mould. The sag time used for the simulations was $0.3 \mathrm{~s}$. After this time the pressurized air forces the preform to obtain the shape of the mould. The glass propagation during sag and blow is shown in Fig. 7. Figure 8 shows the temperature profiles. The time duration of the second blow stage is $1.025 \mathrm{~s}$ 


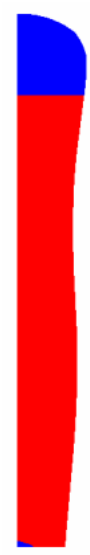

(a) $t=0.0 \mathrm{~s}$

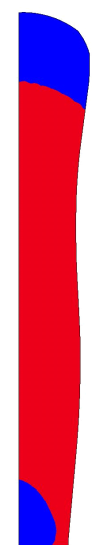

(b) $t=0.25 \mathrm{~s}$

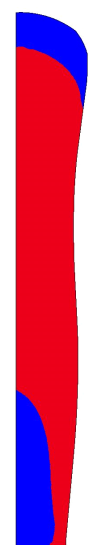

(c) $t=0.75 \mathrm{~s}$

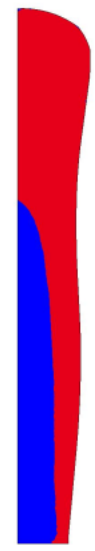

(d) $t=1.75 \mathrm{~s}$

Fig. 5. The glass area propagation of the first blow step of the preform. Air is denoted with blue and glass with red.

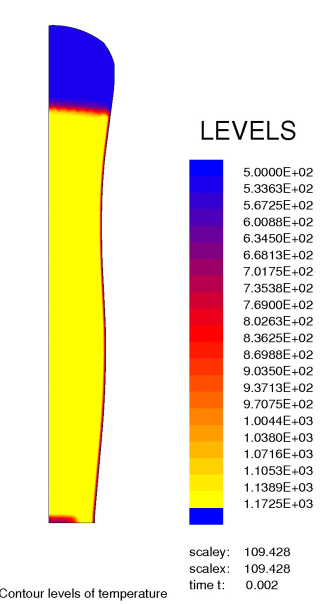

(a) $t=0.0 \mathrm{~s}$

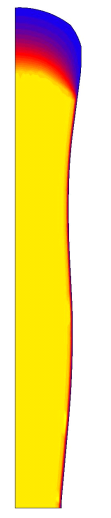

(b) $t=0.25 \mathrm{~s}$

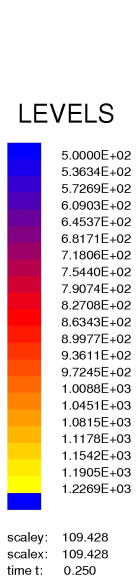

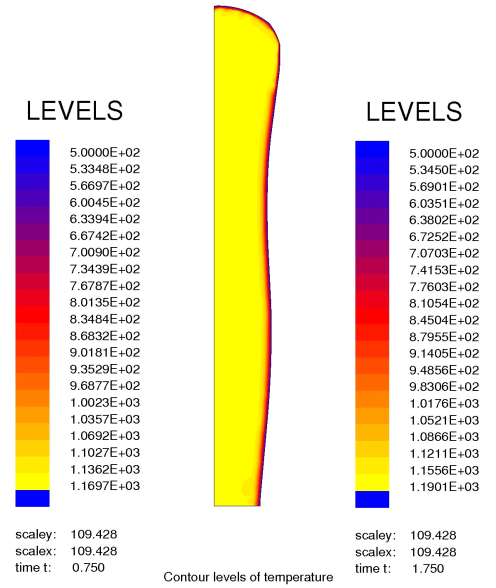

(d) $t=1.75 \mathrm{~s}$

Fig. 6. Temperature profiles of the first blow step of the preform at different times.

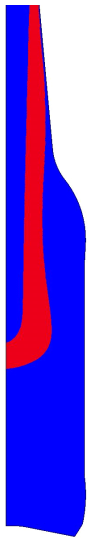

(a) $t=0.0 \mathrm{~s}$

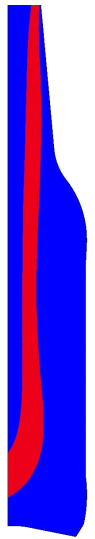

(b) $t=0.3 \mathrm{~s}$

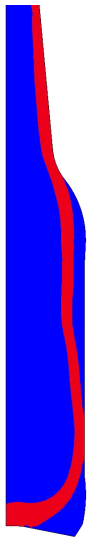

(c) $t=0.725 \mathrm{~s}$

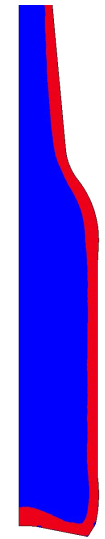

(d) $t=1.025 \mathrm{~s}$

Fig. 7. The glass area propagation of the second blow step of the preform with stretch time $0.3 \mathrm{~s}$. Air is denoted with blue and glass with red.

Figure 9 compares the thickness of the final product in the blow-blow simulation with the thickness data provided by industry. The level set function is used to measure the glass thickness in the simulation. 


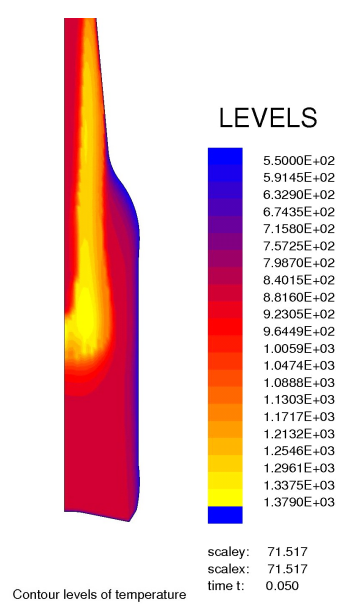

(a) $t=0.0 \mathrm{~s}$

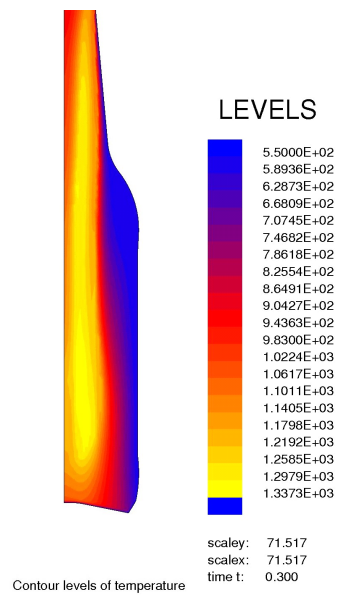

(b) $t=0.3 \mathrm{~s}$

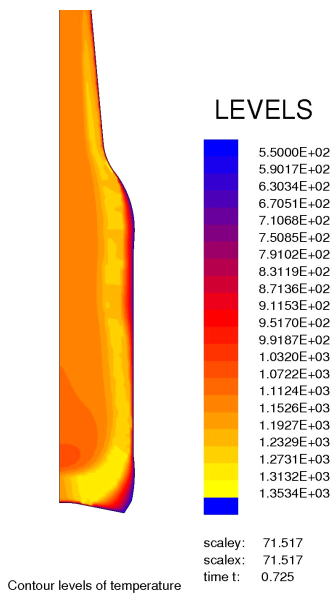

(c) $t=0.725 \mathrm{~s}$

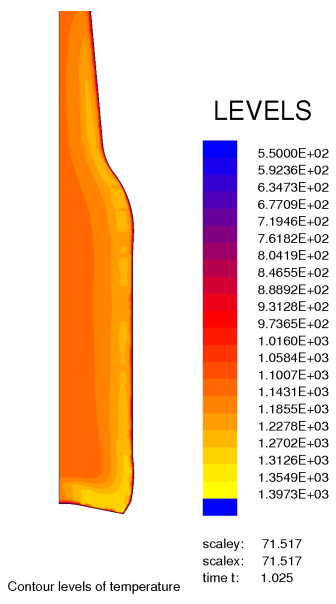

(d) $t=1.025 \mathrm{~s}$

Fig. 8. Temperature profiles of the first blow step of the preform at different times.

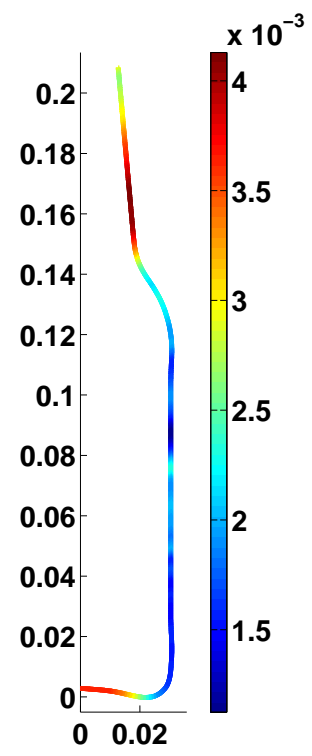

(a) Simulation $[\mathrm{m}]$

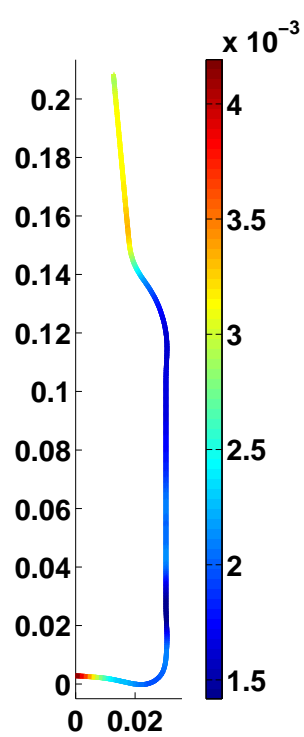

(b) Measurements $[\mathrm{m}]$

Fig. 9. Final product thickness distribution.

In the comparison it should be taken into account that errors in the glass thickness are prone to both modeling and measurement inaccuracies. A relevant issue in this matter is the measurement of the initial glass temperature distribution. The glass temperature was provided by industry, but it is unclear how it was obtained. The most common methods to measure the temperature are by means of thermocouples and single-wavelength pyrometers [23]. In the forming of glass containers thermocouples are impractical $[24,25]$. With a pyrometer it is only possible to determine the surface temperature. Several attempts have been made to determine also the temperature in the glass, however this is usually coupled to significant errors [24, 26, 27]. In [24] it is stated that the accuracy in the measurement of the surface temperature by a pyrometer is typically around $5^{\circ} \mathrm{C}$. Reconstruction of the temperature distribution in the glass from the measured spectral intensity typically results in an error of the order $10^{\circ} \mathrm{C}$.

Figure 10 shows that a temperature difference of $10^{\circ} \mathrm{C}$ results in a thickness variation of nearly the same order as the difference in thickness between Fig. 9(a) and Fig. 9(b). Note that the error of the least squares approximation (29) is of the same order of magnitude as the expected error due to measurements and reconstruction of the temperature distribution in the glass. A more accurate approximation of the temperature data does not give any significant improvement. From this it can be concluded that the computed thickness in the simulation is as near to the measured thickness as can be expected. Thus, taking the expected error into account, the thickness distribution in the simulation is in good agreement with the measured thickness distribution.

In order to further assess the accuracy of the simulation model presented in this paper, the glass volume conservation is used. Figure 11 shows the percentage volume change in time. The volume change has a maximum of $1.5 \%$. The volume 


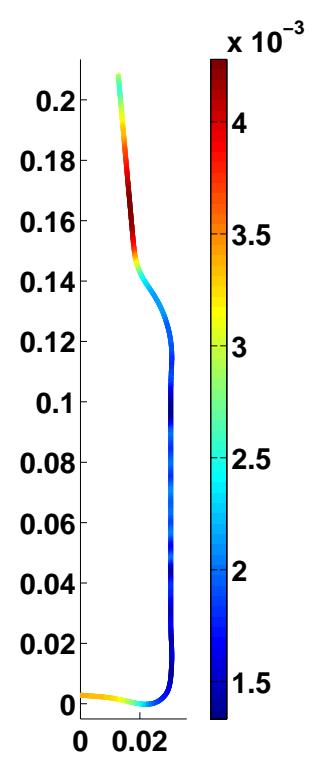

(a) Decrease of $5^{\circ} \mathrm{C}$ in the initial glass temperature

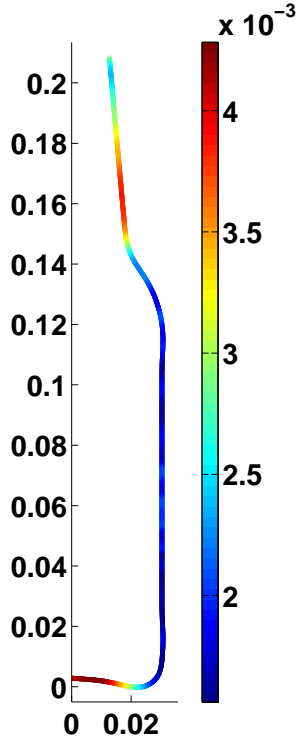

(b) increase of $5^{\circ} \mathrm{C}$ in the initial glass temperature

Fig. 10. Final product thickness distribution for the simulation.

conservation can be further improved using smaller time steps, higher mesh quality and a second order accurate discretisation schemes such as Crank Nicholson. This phenomenon was also observed in [3].

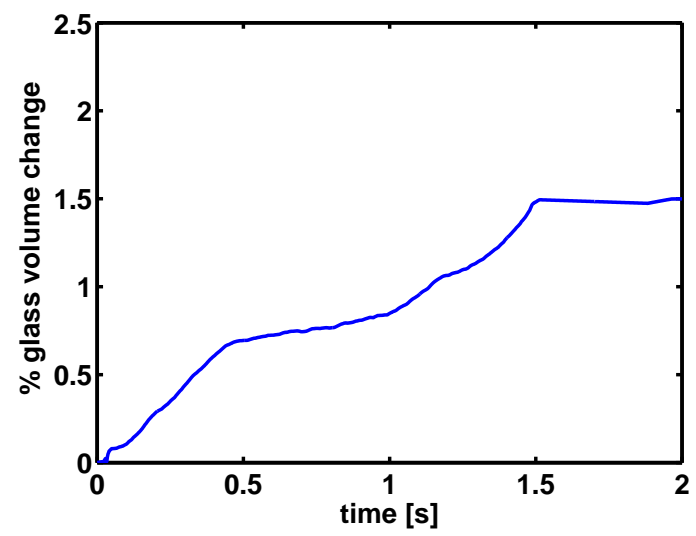

Fig. 11. Volume conservation of the consecutive first and second blow stages using the Euler Implicit time discretisation scheme with time step $1 \mathrm{e}-4$.

\section{Conclusions}

In this paper the implementation of the blow-blow forming process of glass containers tested in realistic manufacturing conditions was presented. Both the first and the second blow stage of the forming process were modeled. A realistic nonuniform temperature distribution of the preform in the second stage was reconstructed using temperature data provided by industry. The fluid flow is described by a Stokes flow problem and the heat transfer by an energy exchange problem. The glass position is modeled by two level set problems corresponding to the inner and outer glass-air interface.

The method was implemented in a finite elements library for both structured and unstructured grids, which enables manufacturers to use it for any possible shape of the end product.

The model is validated by means of several examples regarding conservation properties, behaviour of the flow and comparison of the glass thickness with experimental measurements. The method gave a volume conservation of between $1.5 \%$ which can further be improved using higher order discretisation schemes. Furthermore, taking the expected error in 
the measurement of the glass temperature into account, the thickness distribution in the simulation is in good agreement with the measured thickness distribution provided by industry. This gives confidence that this model can be used for industrial practice.

\section{Achnowledgements}

The authors would like to thank Marie Currie Research Training Networks Fellowships, European Commission for funding this project.

\section{References}

[1] Giannopapa, C. G., 2008. "Development of a computer simulation model for blowing glass containers". J. Man. Sci. Eng., 130.

[2] Tooley, F. V., 1984. The Handbook of Glass Manufacture, Vol II. Aslee Publishing Co, New York.

[3] Krause, D., and Loch, H., eds., 2002. Mathematical Simulation in Glass Technology. Springer, Berlin.

[4] Cormeau, A., Cormeau, I., and Roose, J., 1984. "Numerical simulation of glass-blowing". In Numerical Analysis of Forming Processes, J. F. T. Pittman, O. C. Zienkiewicz, R. D. Wood, and J. M. Alexander, eds. Wiley, New York, pp. 219-237.

[5] César de Sá, J. M. A., 1986. "Numerical modelling of glass forming processes”. Eng. Comput., 3, pp. 266-275.

[6] Hyre, M., 2002. "Numerical simulation of glass forming and conditioning". J. Am. Ceram. Soc., 85(5), pp. $1047-1056$.

[7] César de Sá, J. M. A., Natal Jorge, R. M., Silva, C. M. C., and Cardoso, R. P. R. “A computational model for glass container forming processes". In Europe Conference on Computational Mechanics Solids, Structures and Coupled Problems in Engineering.

[8] Lochegnies, D., Moreau, P., and Guilbaut, R., 2005. “A reverse engineering approach to the design of the blank mould for the glass blow and blow process". Glass Technology, 46(2), pp. 116-120.

[9] Sethian, J. A., 1999. Level Set Methods and Fast Marching Methods. Cambridge University Press, USA.

[10] Sussman, M., Smereka, P., and Osher, S., 1994. "A level set approach for computing solutions to incompressible two-phase flow". J. Comp. Phys, 114, pp. 146-159.

[11] Adalsteinsson, D., and Sethian, J. A., 1995. "A fast level set method for propagating interfaces". J. Comp. Phys, 118, pp. 269-277.

[12] Chang, Y. C., Hou, T. Y., Merriman, B., and Osher, S., 1996. "A level set formulation of eulerian interface capturing methods for incompressible fluid flows". J. Comp. Phys., 124, pp. 449-464.

[13] Shelby, J. E., 2005. Introduction to Glass Science and Technology, second ed. The Royal Society of Chemistry, Cambridge.

[14] Laevsky, K., 2003. "Pressing of glass in bottle and jar manufacturing: Numerical analysis and computation". PhD thesis, Eindhoven University of Technology.

[15] Linden, B. J. v. d., 2002. "Radiative heat transfer in glass: The algebraic ray trace method". PhD thesis, Eindhoven University of Technology.

[16] Cuvelier, C., Segal, A., and Steenhoven, A. A., 1986. Finite Element Methods and Navier-Stokes Equations. Reidel, Dordrecht.

[17] Gunzburger, M. D., 1989. Finite Element Methods for Viscous Incompressible Flows: A Guide to Theory, Practice and Algorithms. Academic Press, New York.

[18] Bathe, K., 1996. Finite Element Procedures. Prentice Hall, Englewood Cliffs.

[19] Vorst, H. A. v. d., 1992. "Bi-cgstab: a fast and smoothly converging variant of bi-cg for the solution of nonsymmetric linear systems”. SIAM J. Sci. Stat. comput., 13(2), pp. 631-644.

[20] Johnson, C., Nävert, U., and Pitkäranta, J., 1984. "Finite element methods for linear hyperbolic problems". Comp. Meth. Appl. Mech. Eng., 45, pp. 285-312.

[21] Brooks, A. N., and Hughes, T. J. R., 1982. "Stream-line upwind/petrov-galerkin formulation for convection dominated flows with particular emphasis on the incompressible navier-stokes equations". Comp. Meth. Appl. Mech. Eng., 32, pp. 199-259.

[22] Allaart-Bruin, S. M. A., Linden, B. J. v. d., and Mattheij, R. M. M., 2006. "Modelling the glass press-blow process". In Progress in Industrial Mathematics at ECMI 2004 (Proceedings 13th European Conference on Mathematics for Industry, Eindhoven, The Netherlands, June 21-25, 2004), A. Di Bucchianico, R. M. M. Mattheij, and M. A. Peletier, eds., Vol. 8 of Mathematics in Industry / The European Consortium for Mathematics in Industry, Springer, Berlin, pp. 351-355.

[23] Nagtegaal, T. M., Rindt, C. M. M., and van Steenhoven, A. A., 2004. "Numerical analysis of an optical method to determine temperature profiles in hot glass melts”. Meas. Sci. Technol., 15, pp. 279-289. 
[24] Viskanta, R., 1975. "Infrared radiation techniques for glass surface and temperature distribution measurements". IEEE Trans. Ind. Appl., IA-11(5), pp. 494-505.

[25] Nagtegaal, T. M., 2002. "Optical method for temperature profile measurements in glass melts". PhD thesis, Eindhoven University of Technology.

[26] Beattie, J. R., and Coen, E., 1960. "Spectral emission of radiation by glass". Br. J. Appl. Phys., 11(5), pp. 151-157.

[27] Viskanta, R., Chupp, R. E., Toor, J. S., and Hommert, P. J., 1975. "Spectral remote sensing of temperature distribution in glass". IEEE Trans. Ind. Appl., IA-11(4), pp. 438-446. 
PREVIOUS PUBLICATIONS IN THIS SERIES:

\begin{tabular}{|c|c|c|c|}
\hline Number & Author(s) & Title & Month \\
\hline II-24 & $\begin{array}{l}\text { L.M.J. Florack } \\
\text { H.C. van Assen }\end{array}$ & $\begin{array}{l}\text { Multiplicative calculus in } \\
\text { biomedical image analysis }\end{array}$ & Apr. 'II \\
\hline II-25 & $\begin{array}{l}\text { F. Lippoth } \\
\text { G. Prokert }\end{array}$ & $\begin{array}{l}\text { Classical solutions for a } \\
\text { one phase osmosis model }\end{array}$ & Apr. 'II \\
\hline II-26 & $\begin{array}{l}\text { M. Rudnaya } \\
\text { R.M.M. Mattheij } \\
\text { J.M.L. Maubach } \\
\text { H.G. ter Morsche }\end{array}$ & $\begin{array}{l}\text { Gradient-based sharpness } \\
\text { function }\end{array}$ & Apr. 'II \\
\hline II-27 & $\begin{array}{l}\text { J.A.W.M. Groot } \\
\text { C.G. Giannopapa } \\
\text { R.M.M. Mattheij }\end{array}$ & $\begin{array}{l}\text { Modelling stretch blow } \\
\text { moulding of polymer } \\
\text { containers using level set } \\
\text { methods }\end{array}$ & Apr. 'II \\
\hline II-28 & $\begin{array}{l}\text { C.G. Giannopapa } \\
\text { J.A.W.M. Groot }\end{array}$ & $\begin{array}{l}\text { Modeling the blow-blow } \\
\text { forming process in glass } \\
\text { container manufacturing: } \\
\text { A comparison between } \\
\text { computations and } \\
\text { experiments }\end{array}$ & Apr. 'II \\
\hline
\end{tabular}

